\title{
Hemoglobin Fraction Pattern
}

National Cancer Institute

\section{Source}

National Cancer Institute. Hemoglobin Fraction Pattern. NCI Thesaurus. Code C161363.

A description of the hemoglobin fraction pattern in a biological specimen. 